\title{
SMART GRID TECHNOLOGIES: TRENDS AND PERSPECTIVES
}

\author{
Anna Buran ${ }^{1, *}$, Gavriil Nizkodubov ${ }^{1}$, and Ilya Pryahin ${ }^{1}$ \\ ${ }^{1}$ National Research Tomsk Polytechnic University, 634050 Tomsk, Russia
}

\begin{abstract}
The study explores the role of Smart Grid technologies, giving sustainable, reliable and safe energy. These technologies will provide an economic benefit to the government, the investors and the consumers. The paper overviews global trends and perspectives of using Smart Grid technologies in Russia and in other countries. The Smart Grid concept is especially important for Russia, because there are many power supply problems in the energy sector. This study is expected to be important for researchers and engineers studying Smart Grid technologies.
\end{abstract}

\section{Introduction}

Any country has a slightly different set of reasons for pursuing smart grid (SG) technologies and programs and a slightly different definition of what constitutes a smart grid. The reason is the energy sector has one of the strategic roles in the development of national industrial complexes, and the world economy as a whole [1]. Generally, smart grids coordinate the needs and capabilities of all generators, grid operators, end-users and electricity market stakeholders to operate all parts of the system as efficiently as possible, minimizing costs and environmental impacts while maximizing system reliability, resilience and stability [2]. The term SG has a lot of definitions, because each country has its own SG strategy and concept. For example, in the European opinion, Smart Grid is a concept of fully-integrated, self-healing and self-regulated electric power system, which has a network topology and includes all generating sources, transmission and distribution networks, all types of electrical energy consumers - driven by a single network of automated devices in real time. At the same time, in the opinion of the USA, SG is a set of organizational changes, new models of the processes, decisions in the field of information technology, as well as innovation in the field of automated control systems and supervisory control in power engineering. Smart Grids can be easily described as "Transactive". This means that the SG has the following characteristics. It will enable new products, services, and markets, as well as active participation by consumers. Also, it will provide power quality for the digital economy and optimize asset utilization. What is more important SG can anticipate and respond to system disturbances. Last feature makes it absolutely secure and means that the SG will operate resiliently against attack and natural disaster. All above mentioned characteristics proved that SG is more effective in comparison with a standard network.

\footnotetext{
*Corresponding author: aburan@tpu.ru
} 


\section{Analysis of using Smart Grid technologies in the East}

Smart Grid technologies offer greater choice between energy providers, products and services to consumers, as well as, greater transparency and control over energy consumption. As for vendors, they will have opportunity for a machine-to-machine platform that can assist multiple industries to create new products and services to take to market; also they can reduce the cost of delivery through mass deployments. The government has real opportunities for GDP uplift and green-collar job creation, moreover, spending efficiency, increased by providing options to rationalize national infrastructure investments. In case of SG implementation utilities can provide grid efficiency, reliability and understanding of power flows which increased enabling operational/maintenance savings. They will have new ways to improve customer service and create new revenue channels, like new opportunities to transition from a commodity provider to a service provider and to evolve the operating model and lower operating costs.

In table 1 the concept of Smart Grid implementation in the South Korea is presented. South Korea prefers National Export Strategy and state-owned monopoly in the capacity of the market model. This means, that government of South Korea has the major influence on the strategic choice and implementation of the SG concept in this country.

Table 1. Smart Grid concept in South Korea.

\begin{tabular}{|c|c|}
\hline Strategy & National Export Strategy \\
\hline Country & $\begin{array}{l}\text { South Korea } \\
\end{array}$ \\
\hline $\begin{array}{l}\text { Local industry } \\
\text { drivers }\end{array}$ & $\begin{array}{l}\text { Development of an industrial complex to export smart grid } \\
\text { technologies and solutions globally; } \\
\text { A green economic growth agenda; } \\
\text { Integrate with other initiatives - intelligent city, electric } \\
\text { vehicles, renewable, transnational supergrid }\end{array}$ \\
\hline Market Model & State-owned monopoly \\
\hline $\begin{array}{c}\text { Regulatory } \\
\text { Incentives for } \\
\text { Smart Grid Pilots }\end{array}$ & $\begin{array}{c}\text { International knowledge sharing programs, e.g. the Korea- } \\
\text { Illinois Smart Grid Collaboration Program; } \\
\text { National smart grid work flowchart }\end{array}$ \\
\hline $\begin{array}{c}\text { IP } \\
\text { development focus }\end{array}$ & $\begin{array}{l}\text { Transmission and distribution solutions; } \\
\text { Storage technology; } \\
\text { Electric vehicles; }\end{array}$ \\
\hline SG maturity & Low - medium \\
\hline $\begin{array}{l}\text { Local industry } \\
\text { challenges }\end{array}$ & $\begin{array}{c}\text { Regional regulatory markets may not be strongly } \\
\text { conducive limiting ability to develop innovation in a local } \\
\text { context }\end{array}$ \\
\hline
\end{tabular}

South Korea prefers National Export Strategy and state-owned monopoly in the capacity of the market model. This means, that government of South Korea has the major influence on the strategic choice and implementation of the SG concept in this country. The South Korean government is planning to reduce CO2 emissions by 2020 . The goal seems to be challenging as Korean plants and factories doubled their emissions over the last decade. With this goal Seoul is trying to be a model for other countries, including, such as India and China, being developing countries under the Kyoto Protocol.

Korea pursues sustainable development, dealing with climate change. It shifts toward a low carbon economy and a society. Following this plan, Korea launches a SG project to achieve green growth in an effective way. The main idea of the project was to enhance the Korean industry. 
The market model of the SG concept is integrated and the country pursues the policy that is aimed at improving the consumer experience. There are a lot of major companies, which exert an influence on the SG implementation: like GE, FreeDM, ABB group and others. The ABB group should be singled out, because, nowadays, this company produces a lot of SG devices and equipment and it realizes at least a third part of all SG projects in the USA. It has some particular projects, like Stockholm Royal Seaport and SG Got land. As well as major projects like "Smart Grid Center of Excellence", which will be created in the near future in Raleigh, state North Carolina. An initial investment of the company in this project will be about $\$ 10$ million. This center will include a testing and development laboratory, a verification center and a demonstration center. One of the important functions of this center will be collaboration with the same center of the company FreeDM and invention and testing of new devices in the USA and in the whole world.

\section{Analysis of of using Smart Grid technologies in Russia}

The Smart Grid concept is urgent for Russia, because of problems in the energy sector, such as the ever more unreliable electric power grids, the necessity of energy supply in many time zones, and the obsolete single-direction energy transmission system. The energy resources in Russia are frequently wasted. Different sources show that losses during the energy distribution in Russia are significantly higher than in the European countries [2]. However, due to the specific economic situation in Russia the Smart Grid concept has become more popular there. The conversion of the Unified National (All-Russia) Electric Grid (UNEG) into the Smart Grid format allows increasing the system reliability of power grid complex, reduces the capital investment into the building of new objects, receives the technical and economical efficiency from the disposition of the UNEG objects in 8 time zones, and decreases the impact of the energy sector on the environment [3]. It's necessary to underline that in the Russian Federation the major power companies are federal, this means, they are regulated by the government and power market trends are chosen by them. One of these companies is the Federal Grid Company of Unified Energy System (FGC of UES). This company, like most power companies in Russia has chosen the SG concept of "Intelligent System" implementation. The advanced investment of capital in the SG technologies will make RUR 952,4 [3,4]. Moreover, this company tries to support and finance national equipment and material manufacturers; they have a special program for them. Also, some pilot projects in Siberia, in the Far East, in North West are realized with the support of this company. In the near future in these regions, there will be mass use of innovation SG techniques: storage batteries with high power, static reactive compensators, modern systems of equipment monitoring and diagnostics. For the full review, another example of SG implementation in our country will be given. It's the Research and Development Center of Smart Grid, which includes National Research Tomsk Polytechnic University; the Institute of Power Engineering; The Energy Research Institute of the Russian Academy of Sciences. National Research Tomsk Polytechnic University is presented by Scientific-research laboratory "Simulation of power systems", which made the invention called "Hybrid fully-variable simulated package of distribution network in real time" in the past. This innovation intends for continuous and high-precision modeling of power systems in real time. What is more important, it has the following specifics: unbounded interval of modeling, modeling in real time, high level of adequacy, profound mathematical model of elements, modeling of the process, which happens to the Power System at the same time. Considering depreciation of electrical equipment and constantly growing demands in the building of new energy facilities, the first step on the way of smart grid implementation is not an intellectualization of existing objects, but building new objects with advanced manufacturing sciences of the power industry. As an example, one 
step of building smart grids is the project of the Federal Grid Company (FGC) which involves the creation of a single automated technological management system. Such a system is oriented to avoid emergency operation, create an online monitoring system and provide smart diagnostics of equipment state. The Smart Grid technology requires the development and integration of a whole complex of innovative equipment and technologies: FACTS, PMU, WAMS, WAPS, WACTS technologies, powerful storage systems, electric vehicles, renewable and hybrid power supply systems based on them.

\section{Conclusion}

Smart grid technologies can be defined as self-sufficient systems that can find solutions to problems quickly in an available system that reduces the workforce and targets quality electricity to all consumers [5, 6]. Moreover, the Smart Grid (SG), are likely to bring out subsequently enormous forms of social change [7] in a modern world. The Smart Grid concept is especially important for Russia, as the integration of new technological advances in the energy systems and information and communication technologies [8] can help solve many of power supply problems in the energy sector of our country.

\section{References}

1. V.M. Rostovtseva, G.A. Nizkodubov, MATEC Web Conf. 72, 01096 (2016)

2. B.B. Kobec, I.O. Volkova, Innovative development of electrical engineering based on the concept "Smart Grid" (IAC Energy, Moscow, 2010) [in Russian]

3. Federal Grid Company of Unified Energy System., http://www.fsk-ees.ru/eng/

4. Smart Grid: China Leads Top Ten Countries in Smart Grid Federal Stimulus Investments, Zpryme Reports, Zpryme Research \& Consulting press release (2010) http://zpryme.com/news-room/smart-grid-china-leads-top-ten-countries-in-smart-gridfederal-stimulus-investments-zpryme- reports.html

5. R. Bayindir, I. Colak, G, Fulli, K. Demirta, Renewable Sustainable Energy Rev. 66, 499 (2016)

6. S. Maier, Reininghaus District. Energy, Sustainability Society 6, 1 (2016)

7. O. Ellabban, H. Abu-Rub, Renewable Sustainable Energy Rev. 65, 1285 (2016)

8. Camarinha-Matos, M. Luís, Renewable Sustainable Energy Rev. 65, 283 (2016) 